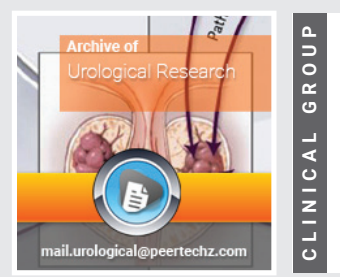

\section{Topical Therapy of Periclitoral Lesions Associated With Dysuria and Pelvic Pain}

\author{
Ingrid A Carlson ${ }^{1 *}$, Richard J Presutti ${ }^{2}$, Ashley M Shumate ${ }^{3}$ \\ and Steven P Petrou ${ }^{3 *}$
}

1Department of Gynecology, Mayo Clinic, Jacksonville, Florida, USA

${ }^{2}$ Department of Family Medicine, Mayo Clinic, Jacksonville, Florida, USA

${ }^{3}$ Department of Urology, Mayo Clinic, Jacksonville, Florida, USA
Received: 16 April , 2020

Accepted: 25 April, 2020

Published: 27 April, 2020

*Corresponding author: Seven P Petrou, Department of Urology, Mayo Clinic, 4500 San Pablo Road, Jacksonville, FL 32224, USA, Tel: 904-953-7330 Fax: 904-953-2218; E-mail: petrou.steven@mayo.edu

Keywords: Clitoral pain; Dysuria; Pelvic pain; Vaginal erosions; Urinary frequency

https://www. peertechz.com

\section{Check for updates}

\begin{abstract}
Background: Chronic dysuria can be diagnostically challenging as it may be a symptom of a variety of conditions, including infectious, inflammatory, hormonal, and neoplastic etiologies. The evaluation of dysuria may encompass multiple diagnostic tests, including cultures, imaging, and instrumentation and lead to the potential overuse of antibiotics and analgesics. We sought to evaluate the association of dysuria and vulvar vestibule pain with periurethral anatomic lesions and response to treatment of same.
\end{abstract}

Methods: Twelve women were referred for evaluation of chronic dysuria and periurethral or periclitoral burning. Patient ages ranged from 17 to 73 years (mean, 51 ; median, 46). All patients had a history of irritating urinary symptoms and dyspareunia and had failed courses of empiric antibiotics with negative urinary cultures. On physical examination, all patients were found to have tender punctate erythematous erosions of the midline periclitoral and periurethral mucosa. For 4 weeks, 3 patients were treated with topical estradiol cream and clobetasol to the periclitoral area and 9 were treated only with topical estradiol cream.

Results: Nine of the 12 patients were available for follow-up, 6 of whom experienced improvement in dysuria and pelvic pain. Two patients did not comply with daily treatment, but were minimally improved. One patient compliant with treatment had minimal improvement in symptoms and underwent diagnostic elliptical excision of lesions under general anesthesia, resulting in complete resolution of periclitoral pain and dysuria postoperatively. Pathology revealed reactive epithelial changes and minimal nonspecific chronic inflammation with periodic acid-Schiff stain negative for fungal organisms.

Conclusions: Periclitoral lesions appear to be a treatable etiology of chronic dysuria and secondary pelvic pain and successful therapy may eradicate these symptoms.

\section{Introduction}

The etiology of chronic dysuria can be diagnostically challenging as it is associated with a variety of conditions, including urinary tract infection, renal or bladder calculi, interstitial cystitis, bladder or urethral neoplasm, urethral diverticulum or stricture, postmenopausal atrophy, vulvar lesions, and vaginitis [1].

In postmenopausal women, dysuria may often be accompanied by other symptoms of genitourinary syndrome of menopause, including dyspareunia, dryness, and sexual dysfunction. Physicians may attribute all of these symptoms to estrogen deficiency, but other differential diagnoses must be considered, including lichen simplex chronicus, lichen sclerosus, lichen planus, and other vaginal dermatoses [2]. For those women who report vulvovaginal symptoms, emotional impact and impact on sexual function are not uncommon [3].

The diagnostic workup of chronic dysuria may include basic urine studies such as urinalysis and culture, urine cytology, and cystoscopy and radiographic imaging. Physical examination should encompass assessment of urethra and vagina for signs of abnormal discharge, lesions, diverticuli, atrophy, and pelvic floor dysfunction. Cultures of the vagina and urethra are often useful in assessing for infection and inflammation as dysuria can be a symptom of vaginitis or urethritis [4].

Well-delineated mucosal lesions of the periclitoral area 
often may not be identified as the primary etiology for dysuria and dyspareunia. This case series identifies patients with chronic dysuria and dyspareunia for whom discreet periclitoral lesions were identified and treated.

\section{Methods}

A retrospective review was performed on twelve women with chronic dysuria and identifiable erythematous periclitoral mucosal lesions, who were evaluated between September 1, 2012 and September 30, 2014. Symptoms included chronic dysuria, periurethral or periclitoral burning, urinary frequency, periclitoral pain, and dyspareunia (Table 1). All patients had a history of empiric treatment with multiple courses of antibiotics, but with negative urine cultures. Five patients had been previously treated for vaginal candidiasis and 1 for pseudomonal vaginitis. All patients were found to have equidistant punctate erosions of the periclitoral and urethral mucosa arranged linearly in the midline crease (Figure 1). The lesions were erythematous and very tender to palpation with a cotton swab. Nonerythematous punctate erosions were also observed, but were found to be nontender.

Three patients were treated with dual therapy consisting of topical estradiol cream for vaginal tissue atrophy combined with clobetasol for inflammation. Nine patients were treated

Table 1: Presenting Symptoms of the 12 Patients.

\begin{tabular}{|c|c|c|c|c|c|c|c|}
\hline Patient & Age & Dysuria & $\begin{array}{c}\text { Urinary } \\
\text { Frequency }\end{array}$ & $\begin{array}{c}\text { Periurethral/ } \\
\text { Periclitoral } \\
\text { Burning }\end{array}$ & $\begin{array}{c}\text { Periclitoral } \\
\text { Pain }\end{array}$ & $\begin{array}{c}\text { Anterior } \\
\text { Dyspareunia }\end{array}$ & $\begin{array}{c}\text { Pelvic } \\
\text { Pressure }\end{array}$ \\
\hline 1 & 73 & YES & YES & YES & YES & YES & YES \\
\hline 2 & 51 & & & YES & & YES & YES \\
\hline 3 & 31 & YES & & YES & YES & YES & \\
\hline 4 & 55 & & & & & YES & \\
\hline 5 & 17 & & YES & & & YES & \\
\hline 6 & 30 & YES & YES & & & YES & \\
\hline 7 & 71 & YES & & YES & & & \\
\hline 8 & 40 & YES & YES & & YES & YES & YES \\
\hline 9 & 54 & & YES & & & & \\
\hline 10 & 52 & & & YES & & YES & \\
\hline 11 & 56 & & YES & YES & & YES & \\
\hline 12 & 23 & YES & YES & YES & YES & & YES \\
\hline
\end{tabular}



Figure 1: Lesion After Topical Therapy. Arrow identifies the nonerythematous periclitoral lesion after treatment, which lies below the erythematous periclitoral lesions. with topical estradiol cream as monotherapy applied twice a day to the periclitoral affected area.

Our study received approval from our institutional review board, and a waiver for informed consent for this retrospective review was granted. Signed consent was obtained from the patient whose photograph is included in this manuscript.

\section{Results}

The mean age of the patients treated was 46 years with a median age of 51 years (range, 17-73). Five patients were premenopausal, 1 was perimenopausal, and 6 were postmenopausal. Nine patients were available for evaluation post-therapy and 3 were lost to follow-up. Seven of the 9 patients seen in follow-up experienced improvement in voiding symptoms and pelvic pain ( 2 pre-, 1 peri-, and 4 postmenopausal), while 2 did not respond to therapy (1 preand 1 postmenopausal). All 3 patients on dual therapy had a clinical response in contrast to 4 of the 6 monotherapy patients.

Follow-up examination revealed visual improvement of the erythematous periclitoral lesions in 3 patients ( 2 preand 1 postmenopausal) where lesions were still present, but erythema was improved. There was complete resolution of the erythema in periclitoral lesions in 3 ( 1 peri-, and 2 postmenopausal; and these patients had experienced marked improvement in symptoms. One patient had a limited response to therapy based on visual appearance (postmenopausal, dual therapy) and had resolution of erythema in only 1 of 4 lesions (Figure 1). She subsequently underwent diagnostic elliptical excision of these lesions under general anesthesia, resulting in complete resolution of periclitoral pain and dysuria. Pathology revealed reactive epithelial changes and minimal nonspecific chronic inflammation with periodic acid-Schiff stain negative for fungal organisms.

\section{Discussion}

Topical therapy to the vaginal tissue is frequently used for various gynecologic health disorders. Patients are often treated with topical estradiol cream for treatment of recurrent urinary tract infections in the presence of vulvar and urethral atrophy. ${ }^{5}$ Erythematous periclitoral atrophic erosions appear to be an etiology of chronic dysuria and dyspareunia.

It is possible that in some patients with symptoms of recurrent urinary tract infection, treatment with estradiol cream may be effective because it provides treatment for a discreet mucosal lesion rather than only addressing atrophic changes. While nonerythematous punctate erosions can be observed in the periclitoral midline in asymptomatic women with atrophy, erythema of these erosions appears to be associated with extensive symptomatology. In this case series, identification of a previously unknown lesion in the midline between the clitoris and urethra was observed and initially thought to be associated with atrophy. Multiple patients had been seen by previous physicians with infectious etiology ruled out, including negative herpes simplex testing. Because of the erythema, clobetasol was used to decrease inflammation and estradiol was applied to address atrophy. After improvement 
was observed using this dual therapy, we elected to proceed with monotherapy with estradiol because of concerns of promoting atrophy in the periurethral area with extended use of clobetasol. It was observed that patients continued to improve with estradiol cream alone. Whether dual or monotherapy is superior may be the focus of further research.

Further studies are also needed to determine the prevalence of midline periclitoral atrophic erosions in asymptomatic women and whether women are at increased risk for significant dysuria if the lesions become inflamed. The etiology of these lesions is unclear. Although the erosive lesions appear in some cases to be associated with atrophy, there is a wide age range and associated menopausal status in this case series.

Of interest was the dramatic, immediate clinical response of the patient who underwent surgical excision. The risks of surgical excision in this area may include injury to the urethra or clitoris, resulting in significant pain and sexual dysfunction, and was only undertaken in this case as a diagnostic procedure. However, excisional biopsy may provide a surgical option for lesions that do not respond to medical therapy.

\section{Conclusions}

We review this case series of 12 women with dysuria and dyspareunia who presented with negative urine cultures and erythematous punctate lesions of uncertain etiology in the midline periclitoral area. Identification of these lesions required a thorough pelvic examination. Treatment with estradiol cream or a combination of topical clobetasol and estradiol cream appears to be associated with visual and symptomatic resolution of these lesions. Identification and treatment of erythematous periclitoral lesions may provide a good clinical response for those presenting with aseptic dysuria or dyspareunia. Further investigation of the etiology of these lesions may present new options for treatment for affected persons.

\section{Acknowledgments}

We would like to acknowledge Tri A. Dinh, MD for his assistance in the surgical evaluation of our mutual patient. This case series was written while working in the Department of Gynecology at Mayo Clinic in Jacksonville, Florida.

\section{References}

1. Michels TC, Sands JE (2015) Dysuria: Evaluation and differential diagnosis in adults. Am Fam Physician 92: 778-786. Link: https://bit.ly/2zuXRI8

2. Marnach ML, Torgerson RR (2017) Vulvovaginal issues in mature women Mayo Clin Proc 92: 449-453. Link: https://bit.ly/2Y5YwtU

3. Erekson EA, Li FY, Martin DK, Fried TR (2015) Vulvovaginal symptoms prevalence in postmenopausal women and relationship to other menopausal symptoms and pelvic floor disorders. Menopause 23: 368-375. Link: https://bit.ly/3bHzXY4

4. French L, Phelps K, Pothula NR, Mushkbar S (2009) Urinary problems in women. Prim Care 36: 53-71. Link: https://bit.ly/3cPUXMz

5. Rahn DD, Carberry C, Sanses TV, Mamik MM, Ward RM, et al. (2014) Vaginal estrogen for genitourinary syndrome of menopause. Obstet Gynecol 124: 1147-1156. Link: https://bit.ly/2W1khbH
Discover a bigger Impact and Visibility of your article publication with

Peertechz Publications



* Signatory publisher of ORCID TDNet, Base (Bielefeld University Library) CrossRef, Scilit, J-Gate etc.

Increased citations of published aticles through promotions

Submit your articles and experience a new surge in publication services

Peertechz journals wishes everlasting success in your every endeavours.

Copyright: ( $) 2020$ Carlson IA, et al. This is an open-access article distributed under the terms of the Creative Commons Attribution License, which permits unrestricted use, distribution, and reproduction in any medium, provided the original author and source are credited. 